\title{
EGFR/HER2 Inhibitor AP32788
}

National Cancer Institute

\section{Source}

National Cancer Institute. EGFR/HER2 Inhibitor AP32788. NCI Thesaurus. Code C126752.

An orally available inhibitor of specific mutant forms of both human epidermal growth factor receptor (EGFR) and human epidermal growth factor receptor 2 (HER2; ERBB2), with potential antineoplastic activity. Upon oral administration, EGFR/HER2 inhibitor AP32788 specifically and irreversibly binds to and inhibits certain mutant forms of EGFR and HER2. This prevents EGFR- and HER2-mediated signaling and leads to cell death in EGFR mutant- and HER2 mutant-expressing tumor cells. EGFR and HER2, receptor tyrosine kinases mutated in many tumor cell types, play key roles in tumor cell proliferation and tumor vascularization. 